\title{
A clinical study of elective hysterectomies for benign lesions
}

\author{
Mamta Meena $^{1}$, Urvashi ${ }^{2}$, C. P. Kachawaha ${ }^{3}$, Dharmendra Singh Fathepuriya ${ }^{2 *}$
}

\begin{abstract}
${ }^{1}$ Department of Obstetrics and Gynaecology, Dr. S. N. Medical College, Jodhpur, Rajasthan, India
${ }^{2}$ Department of Obstetrics and Gynaecology, JLN Medical College, Ajmer, Rajasthan, India

${ }^{3}$ Department of Obstetrics and Gynaecology, Dr. S. N. Medical College, Jodhpur, Rajasthan, India
\end{abstract}

Received: 11 April 2021

Accepted: 05 May 2021

\author{
*Correspondence: \\ Dr. Dharmendra Singh Fathepuriya \\ E-mail: dsf857@gmail.com
}

Copyright: () the author(s), publisher and licensee Medip Academy. This is an open-access article distributed under the terms of the Creative Commons Attribution Non-Commercial License, which permits unrestricted non-commercial use, distribution, and reproduction in any medium, provided the original work is properly cited.

\begin{abstract}
Background: Hysterectomy is widely used for treating a variety of gynecologic conditions. Most hysterectomies are elective and are performed to treat benign indications. Hence the present study was undertaken to determine the benign indication of hysterectomy, choice of surgical approach, safety and clinical aspect of hysterectomy as a surgical procedure and to correlate the findings with histopathological reports of the specimen.

Methods: The present series represents a clinical study of 120 cases of elective hysterectomies for benign lesions. Out of which 73 were done by abdominal and 47 by vaginal route. Finally, all operated specimen were subjected to histological examination.

Results: The main indications for elective hysterectomy were leiomyoma 53 (44.2\%), prolapse 47 (39.2\%) and dysfunctional uterine bleeding $11(9.2 \%)$. Type of operation performed were mainly total abdominal hysterectomy with bilateral salphingo-oophorectomy in $60 \%$ cases and vaginal hysterectomy with anterior and posterior repair in $38.3 \%$ cases. The mean duration of surgery and average blood loss was more in vaginal procedure (90 min and $100 \mathrm{ml}$ ) compared to abdominal $(70 \mathrm{~min}$ and $80 \mathrm{ml})$ respectively. Vaginal hysterectomy was associated with less morbidity and a smoother convalescence than abdominal hysterectomy. In $81.2 \%$ cases of abdominal hysterectomies correspondence of indication with histopathological report (HPR) were found, in vaginal $74.5 \%$ cases corresponded their histopathological report with their symptoms and investigations. Associated adnexal pathology was found in $8.3 \%$ cases. There was no mortality during the whole study period.
\end{abstract}

Conclusions: Hysterectomy for benign pelvic lesions is a safe procedure and an important component of health care for women.

Keywords: Abdominal, Benign, Histopathology, Hysterectomy, Leiomyoma, Vaginal

\section{INTRODUCTION}

Uterus, a vital reproductive and hormone responsive organ is subjected to many benign and malignant diseases. Fibroid or leiomyoma is the most common tumour in women during the reproductive years, account for one third $(30 \%)$ of hysterectomies and one fifth of gynaecological visits increase in size and frequency as women age but revert in size postmenopausally. ${ }^{1}$ Many treatment options are available including medical, conservative and surgical but still a hysterectomy, the surgical removal of the uterus, are after caesarean delivery, one of the most common surgical procedures having a rate of $6.1-8.6 / 1000$ in all ages because it is associated with higher rates of patient satisfaction than are other treatments. ${ }^{2}$ However, compared to a higher frequency of hysterectomy (10-20\%) in other countries, a lower rate $(4-6 \%)$ has been reported from India. Higher tolerance threshold of Indian women, low level of medicalization, illiteracy, poverty and cultural suies have been proposed as the reasons for this lower rate. ${ }^{3}$

Moreover, there are different types of hysterectomies and types according to route of hysterectomy include 
abdominal, vaginal, laparoscopic, or combined approaches. ${ }^{4}$ Vaginal hysterectomy is associated with a decreased incidence of complication, to reduce pain, tissue damage, blood loss, postoperative recovery time and avoidance of visible scar, speedier return to normal activities, and fewer abdominal wall infections by least disruption of normal tissue, shorter length of hospital stay and convalescence, reduced hospital charges and better quality of life outcomes while abdominal hysterectomy is associated with longer hospital stay, increased complication and higher cost but due to practice style, training habits and performance of gynaecologist, most of the gynaecologist still continue to use abdominal approach for hysterectomies that could be performed vaginally. ${ }^{5}$ Abdominal route is the choice for more serious pathologies and vaginal route is appropriate for less serious disease. ${ }^{6-8}$ The indications for abdominal or vaginal hysterectomy have changed little over the last decade. Hence, the present study was carried out to determine the indication of hysterectomy, choice of surgical approach, safety and clinical aspect of hysterectomy as a surgical procedure and to correlate the findings with the histopathological reports of the specimen.

\section{METHODS}

A prospective and randomized study was conducted in the Department of Gynaecology and Obstetrics at Dr S.N. Medical College, Jodhpur, during the period from April 2010 to October 2011.Total 120 cases were selected primarily on the basis of clinical history and physical examination, aided by the following ancillary measures in some of the cases.

Diagnostic endometrial curettage after dilatation were done in cases with menstrual irregularities over 39yr age, postmenopausal bleeding and PCOD.

Cervical biopsies were taken in some cases of marked cervical erosion and in suspected cases of malignancy.

Pap's smear in cases of chronic cervicitis.

\section{Ultrasonography.}

Routine pre-operating investigations and preparation were done. Each patient received intravenous antibiotic prophylaxis with broad spectrum coverage; a glycerine enema was administered the night before surgery. Types of hysterectomies performed were- abdominal and vaginal, depending on the type of lesion that an individual had, age and general condition of the patient. All abdominal hysterectomies were done by modified Richardson's techniques or with slight variation, depending on the choice of the operating surgeon. Vaginal hysterectomies were done by Heaney's technique with or without slight modifications. In most cases adnexae were left behind and in only one case one of them removed. Post-operative catheterization and vaginal packing was done in all the cases. The operation was performed by senior gynaecologists and assisted by resident doctors. The technique of operation was almost similar with minor variation. Finally all operated specimen were subjected to histological examination.

Post-operatively Foleys catheter was removed on day 3 in abdominal and day 5 in vaginal hysterectomy group. Vaginal packing was removed on day 3 and perineum care was done twice a day in vaginal hysterectomy group and abdominal first dressing was done on day 4 and second on day 6 in abdominal hysterectomy group. Outpatient follow up was done on 1 month. The data was collected as per Performa. Histopathology reports were collected from Department of Pathology and their diagnosis ware noted, data were analysed by using percentages. Incidence of hysterectomies for benign lesions was calculated after taking in to account the total number of gynaecological cases admitted in the Department of Gynaecology and Obstetrics during the study period.

\section{RESULTS}

Table 1: Distributions of cases according to clinical diagnosis.

\begin{tabular}{|lll|}
\hline Diseases & $\begin{array}{l}\text { No. of } \\
\text { cases }\end{array}$ & Percentage \\
\hline Leiomyoma uteri & 53 & 44.2 \\
\hline $\begin{array}{l}\text { Dysfunctional uterine } \\
\text { bleeding }\end{array}$ & 11 & 9.2 \\
\hline Prolapse & 47 & 39.2 \\
\hline $\begin{array}{l}\text { Post-menopausal } \\
\text { bleeding per vaginum }\end{array}$ & 5 & 4.2 \\
\hline Ovarian cyst & 3 & 2.5 \\
\hline Mental retardation & 1 & 0.83 \\
\hline Cervical polyp & 2 & 1.7 \\
\hline $\begin{array}{l}\text { sPelvic inflammatory } \\
\text { disease }\end{array}$ & 3 & 2.5 \\
\hline Ovarian mass & 1 & 0.83 \\
\hline Adenomyosis & 3 & 2.5 \\
\hline
\end{tabular}

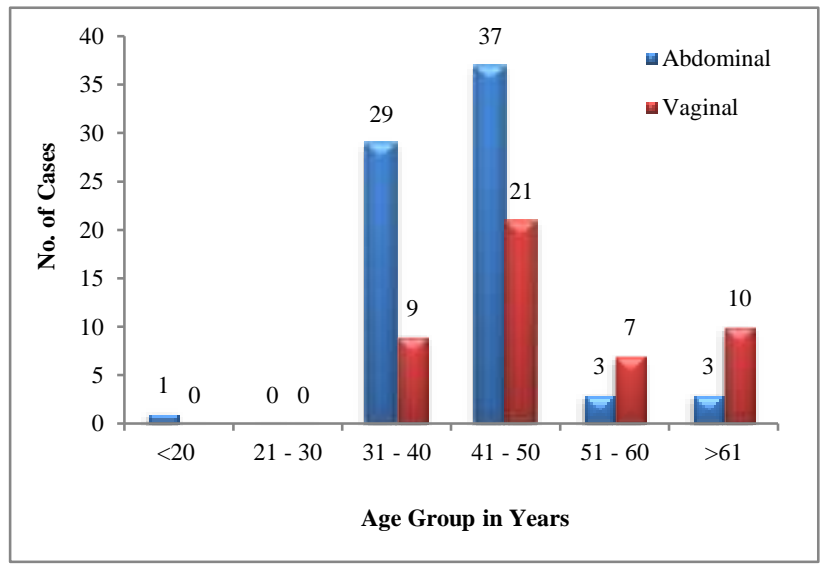

Figure 1: Distribution of patients according to age. 
Among 120 cases of elective hysterectomies, 73(60.8\%) were done by abdominal and $47(39.2)$ by vaginal route. Most of the cases were Hindus, belonging to middle $(50.8 \%)$ and low class $(48.3 \%)$ families, also belonged to rural population $(62 ; 51.7 \%)$ and only $25 \%$ cases were literate. $116(96.66 \%)$ cases were multiparae. The maximum numbers of abdominal and vaginal hysterectomy were done in the age group $41-50$ years as shown in Figure 1.

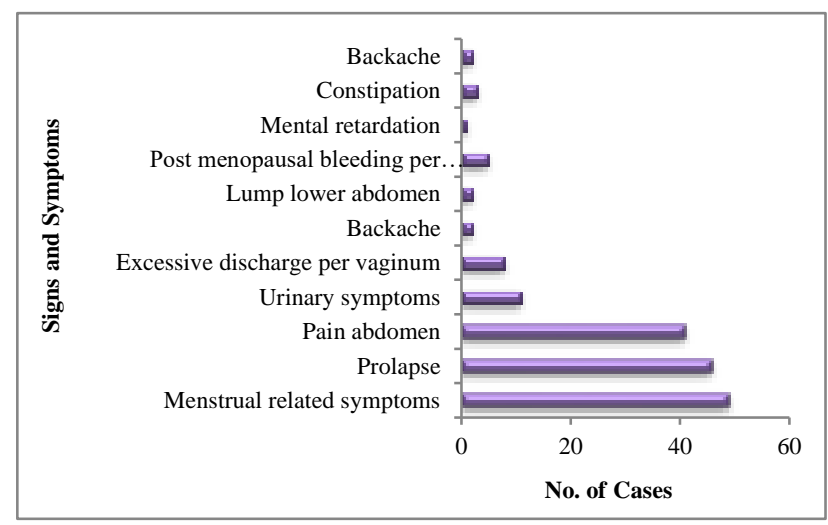

Figure 2: Distributions of cases according to signs and symptoms.

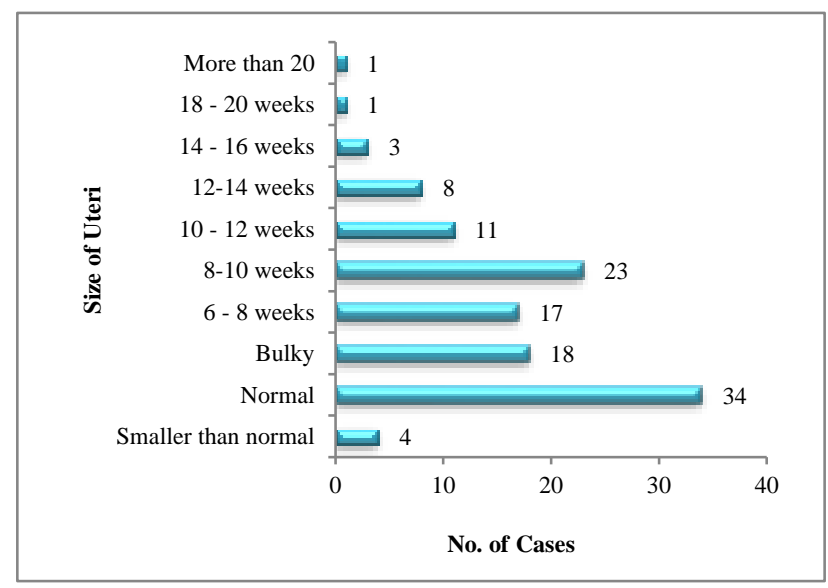

Figure 3: Size of uteri removed in 120 cases of elective hysterectomies.

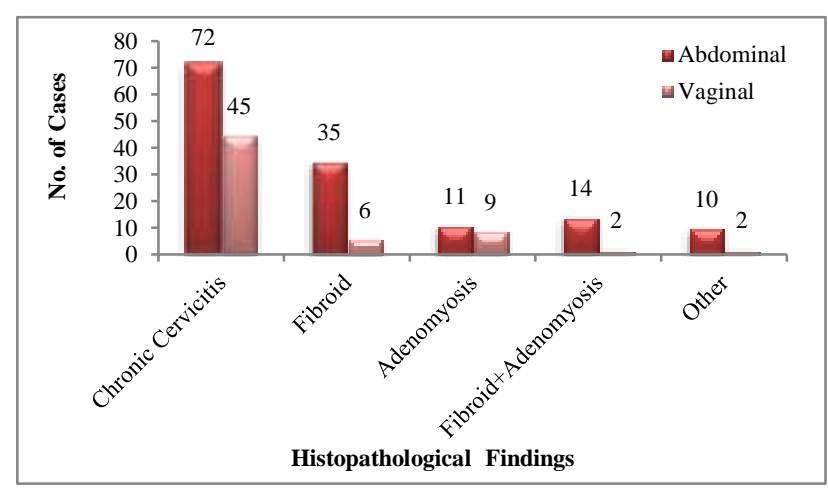

Figure 4: Histopathological findings in the specimens in relation to type of hysterectomy.
The most common presenting features were menstrual related symptoms $(40.8 \%)$ and second were prolapsed $(38.3 \%)$ as depicted in Figure 2.

The principle indication for elective hysterectomy were leiomyoma 53 (44.2\%), prolapsed 47 (39.2\%) and dysfunctional uterine bleeding $11(9.2 \%)$, (Table 1). Most of the cases of leiomyoma were found in the age group $31-50 \mathrm{yr}(90.6 \%)$, functional uterine bleeding occurred within the age group of 41-50yr (70\%) and maximum number of prolapsed occurred in the age group of 41$50 \mathrm{yr}(44.7 \%)$.

Table 2: Post-operative morbidity and complications.

\begin{tabular}{|c|c|c|c|}
\hline Complications & Abdominal & Vaginal & Total \\
\hline Fever & $9(12.3 \%)$ & $\begin{array}{l}10 \\
(21.3 \%)\end{array}$ & $\begin{array}{l}19 \\
(15.8 \\
\%)\end{array}$ \\
\hline Wound sepsis & $2(2.7 \%)$ & $0(0.0 \%)$ & $\begin{array}{l}2 \\
(1.7 \%)\end{array}$ \\
\hline $\begin{array}{l}\text { Urinary } \\
\text { problems }\end{array}$ & $4(5.5 \%)$ & $0(0.0 \%)$ & $\begin{array}{l}4 \\
(3.3 \%)\end{array}$ \\
\hline $\begin{array}{l}\text { Abdominal } \\
\text { distension }\end{array}$ & $0(0.0 \%)$ & $0(0.0 \%)$ & $\begin{array}{l}0 \\
(0.0 \%)\end{array}$ \\
\hline paralytic ileus & $3(4.1 \%)$ & $0(0.0 \%)$ & $\begin{array}{l}3 \\
(2.5 \%) \\
\end{array}$ \\
\hline Bed sore & $1(1.4 \%)$ & $0(0.0 \%)$ & $\begin{array}{l}1 \\
(0.83 \\
\%) \\
\end{array}$ \\
\hline $\begin{array}{l}\text { Secondary } \\
\text { hemorrhage }\end{array}$ & $0(0.0 \%)$ & $0(0.0 \%)$ & $\begin{array}{l}0 \\
(0.0 \%)\end{array}$ \\
\hline $\begin{array}{l}\text { Blood } \\
\text { transfusion } \\
\text { reaction }\end{array}$ & $0(0.0 \%)$ & $1(2.1 \%)$ & $\begin{array}{l}1 \\
(0.83 \\
\%)\end{array}$ \\
\hline $\begin{array}{l}\text { Nausea and } \\
\text { Vomiting }\end{array}$ & $2(2.7 \%)$ & $3(6.4 \%)$ & $\begin{array}{l}5 \\
(4.2 \%)\end{array}$ \\
\hline Diarrhea & $2(2.7 \%)$ & $1(2.1 \%)$ & $\begin{array}{l}3 \\
(2.5 \%) \\
\end{array}$ \\
\hline Others & $3(4.1 \%)$ & $4(8.5 \%)$ & $\begin{array}{l}7 \\
(5.8 \%)\end{array}$ \\
\hline
\end{tabular}

Associated diseases were seen in 40 (33.3\%) cases. Anaemia was present in $7.5 \%$ cases at the time of admission. Apart from anaemia, other associated diseases were hypertension (5.8\%), tuberculosis (4.2\%), bronchial asthma $(1.7 \%)$, diabetes mellitus and hypothyroidism in $0.83 \%$ cases each which was treated by specialist's consultations.

Out of 120 cases, $72(60 \%)$ underwent total abdominal hysterectomy with bilateral salpingo-oophorectomy, bilateral adnexa was conserved in $1(0.83 \%)$. Vaginal hysterectomy with anterior and posterior repair was done in $46(38.3 \%)$, with additional removal of unilateral adnexa in $1(0.83 \%)$. Average time taken during abdominal procedure was 70 minutes and 90 minutes in vaginal procedure. Average blood loss was $80 \mathrm{ml}$ in abdominal group and $100 \mathrm{ml}$ in vaginal group of 
hysterectomies. Size of uteri removed varied from smaller than normal to more than 20weeks of pregnant uterus size as shown in Figure 3.

Post-operative morbidity occurred in $29.2 \%$ cases, most common being fever $15.8 \%$, wound sepsis in $1.7 \%$ cases in both the routes as shown in Table 2 . No case of burst abdomen reported, while only 2 patients developed resuturing in supra-pubic transverse incision. In maximum number of cases $(90 ; 91.7 \%)$ post-operative stay was within 10 days with mean stay period was 8.41 days.

On the basis of histopathological report, most common finding in abdominal and vaginal hysterectomy was chronic cervicitis $(72 ; 98.6 \%$ and $45 ; 95.7 \%$ respectively) as depicted in Figure 4.

Most cases showed proliferative endometrium, 5\% cases showed markedly unhealthy cervix. Secondary operations were necessary in 2 cases as resuturing. In 52 (81.2\%) cases of abdominal hysterectomies correspondence of indication with histopathological report were found, in vaginal $35(74.5 \%)$ cases corresponded their histopathological report with their symptoms and investigations. Associated adnexal pathology was found in $8.3 \%$ cases. New symptoms reported following the hysterectomy were problem related to scar and vault in 2 cases each and vaginal discharge and pelvic pain in 1 case each. There was no mortality during the whole study period.

\section{DISCUSSION}

In the present study, incidence of hysterectomies done amongst the total number of gynecological admissions was $35.3 \%(120 / 340)$ of which the incidence of abdominal hysterectomy was $21.4 \%$ and vaginal hysterectomy was $3.8 \%$. This incidence was comparable with Fatehpuriya et al study and more than Parveenet al study because of non-availability of newer techniques in our hospital, hysterectomy continue to be the main treatment option for benign gynecological diseases. ${ }^{9,10}$ The commonest surgical approach was abdominal hysterectomy $(60.8 \%)$ followed by vaginal hysterectomy $(39.2 \%)$ ratio being 1.5 which is similar to other studies. ${ }^{11,12}$ The peak age incidence of patients was 41-50 years, while the mean parity was 4 , such figures are comparable to those reported in previous studies. ${ }^{12-14}$ This is because the frequency of most common indication for abdominal hysterectomy i.e. leiomyoma, adenomyosis peak in the age group 31-50yr. Pelvic organ prolapse occurred in old women with peak frequency of 51-60yr (peri and postmenopausal) but in our region due to early first delivery, delivery at home by dais, multiparity with early resumption of their homework, poor nutrition and anaemia and house wife working in squatting position (dusting, moping cloth washing, and cooking) it occurs earlier, equalizing the age of abdominal hysterectomy. As far as hysterectomies are concerned in younger ages conservative surgeries would have been the choice of treatment we are lacking and not performing in our institution.

The most common presenting features were menstrual related symptoms $(40.8 \%)$ followed by prolapse $(38.3 \%)$ which was similar in sequence to Qamar-ur-nisa et al. ${ }^{15}$ The principle indications for elective hysterectomy group were leiomyoma $(44.2 \%)$ which was somewhat similar TABLEincidence reported by earlier studies. ${ }^{9,15}$ The second common complaint reported was prolapse 47 cases, all vaginal hysterectomies were done for prolapse which was associated in one case with fibroid uterus which is comparable to study done by Ajmera et al. ${ }^{16}$ As most of the cases of leiomyoma in the present study were multipara indicates that high parity has a definite relationship with uterine pathology.

Anaemia was more common associated disease in patients who underwent abdominal hysterectomies because of prevalence of fibroid and DUB. Hypertension was equally associated with abdominal and vaginal which is justified as hypertension is disease of advancing age. Dilation and curettage prior to surgery was done in 28 $(23.3 \%)$ cases. In almost all cases it was done in premenstrual phase or in menstrual phase when patient was bleeding profusely. Sterilization is a coincidental procedure which is unrelated to the major operation done here; in 10 DUB cases only one case had sterilization which disproves the myth of relationship of DUB with sterilization. The hormonal therapy was given to 13 $(10.8 \%)$ DUB cases as prime treatment and when failed hysterectomy was taken for refractory case. It was also given in fibroid to control heavy bleeding. Due to safety, common practice, and cost effectively, spinal anaesthesia was given to all except two cases in whole study. In two cases of vaginal hysterectomy epidural was given as it served the purpose of PG teaching for residents.

Out of 73 cases of abdominal hysterectomy, supra-pubic transverse incisions were given in $70(95.9 \%)$ cases while $3(4.1 \%)$ cases received sub- umbilical midline incision. The incidence of wound sepsis was reported only in 2 cases of transverse incision. All three sub-umbilical incision were given in indicated patients i.e. one adenomyosis, one fibroid and one ovarian mass-all were bigger in size. Some experienced surgeons preferred suprapubic transverse incision even in big size uteri. In abdominal hysterectomies ovaries were removed unilaterally or bilaterally if required and in vaginal hysterectomies anterior and posterior repair was done in almost all cases as all patients had cystocele and rectocele. We prefer total abdominal hysterectomy over subtotal abdominal hysterectomy, although the debate of preference over each other is burning topic in recent era. Most of the patients in both types of hysterectomies with enlarged uteri were diagnosed as cases of leiomyoma while most cases of normal $8 \mathrm{wk}$ size uteri were diagnosed as cases of functional uterine bleeding and prolapse uterus. More than $10 \mathrm{wk}$ uteri were $31.5 \%$ and $>14 \mathrm{wk}$ (in abdominal hysterectomy group) were 
$5(6.8 \%)$ in number, $1.7 \%$ were more than $18 \mathrm{wk}$ (in abdominal hysterectomies), this shows the delay done by patient due to illiteracy and negligence. We took more time in vaginal hysterectomies than abdominal, reason being that we (senior and junior doctors and residents) are more accustomed to abdominal hysterectomies and vaginal is reserved only for prolapsed uterus. We know that surgery is art of practice and training. In vaginal hysterectomy groups, blood was transfused to $74 \%$ patients as compared to $60.2 \%$ in abdominal hysterectomy group because more bleeding occurred in vaginal hysterectomies. These findings are correlated well with the previous studies..$^{9,12,14,17}$

Vaginal route had less chance of post-operative complications as it is less invasive surgery with comparatively lesser disruption of tissue i.e. it avoids the dissection of skin, muscle, sheath, big portion of peritoneum and it also avoids handling of gut, similar to study conducted by AL-Kadri et al. ${ }^{18}$ As all hysterectomies were done post-menstrualy hence endometrium in maximum cases were in proliferative phase, fibroid and DUB being hyper-estrogenism and anovulatory would have proliferative endometrium. It is very surprising that on histopathology 119 cases out of 120 had chronic non-specific cervicitis by HPR, even it was present in the only teenager's report. It seems that the minimum criteria for chronic cervicitis were used by pathologist or may be due to poor hygienic condition and habit of neglecting of symptoms in Indian women. In one case of abdominal hysterectomy for fibroid there was dysplasia. As post-operative antibiotic were routinely given, the pap smear of vault at one month follow up was normal. In 4 cases of fibroid, HPR of tube showed tubal infiltration in one dilatation of tubes in two cases and associated endometriosis in one cases.

Histopathological reports of $52(81.2 \%)$ cases of abdominal hysterectomy correspond with their indications for surgery. Pre-operative clinical diagnosis was correct in $52(81.2 \%)$ cases while wrong in 21 $(28.8 \%)$ cases of abdominal hysterectomies when compared to final diagnosis of histopathological report while only $35(74.5 \%)$ cases of vaginal hysterectomy were correct and $12(25.5 \%)$ cases were wrong, when their pre-operative diagnosis was compared with histopathological report.

These results are in accordance with the study done by Fatehpuriya et al and Sreedhar et al. ${ }^{9,19}$ The most common finding of ovary, on the basis of histopathological reports, were physiological ovarian cysts 58(48.3\%), normal in 56 $(46.7 \%)$ and pathological findings were reported in $6(5 \%)$.

Only 5 cases had problems in vaginal hysterectomy while this number was 9 in abdominal hysterectomy. There was no mortality amongst the cases of elective hysterectomies for benign lesions similar to study conducted by Parveen et al. ${ }^{10}$

\section{CONCLUSION}

From the results of present study it can be concluded that hysterectomy for benign pelvic lesions is a safe procedure and an important component of health care for women. The results of elective hysterectomies were good in $70.8 \%$ cases while fair in $29.2 \%$ cases. Number of abdominal hysterectomies done was more than that of vaginal hysterectomies (73:47). Chief indication for abdominal was leiomyoma uterus and that for vaginal was pelvic relaxation. Vaginal hysterectomy was associated with less morbidity and a smoother convalescence than abdominal hysterectomy.

\section{Funding: No funding sources \\ Conflict of interest: None declared \\ Ethical approval: Not required}

\section{REFERENCES}

1. Kjerulff KH, Erickson BA, Langenberg PW. Chronic gynecological conditions reported by US women: findings from the National Health Interview Survey, 1984 to 1992. American J Public Health. 1996;86(2):195-9.

2. Dwyer N, Hutton J, Stirrat GM. Randomised controlled trial comparing endometrial resection with abdominal hysterectomy for the surgical treatment of menorrhagia. BJOG: An International Journal of Obstetrics \& Gynaecol. 1993;100(3):237-43.

3. Hysterectomies rate for benign conditions in USA, 1994-2003. Obstet Gynecol. 200;107(6):1278-83.

4. Johnson N, Barlow D, Lethaby A, Tavender E, Curr L, Garry R. Methods of hysterectomy: systematic review and meta-analysis of randomised controlled trials. Bmj. 2005;330(7506):1478.

5. Wu JM, Wechter ME, Geller EJ, Nguyen TV, Visco AG. Hysterectomy rates in the United States, 2003. Obstetrics \& Gynecol. 2007;110(5):1091-5.

6. Gupta S, Manyonda I. Hysterectomy for benign gynaecological disease. Current Obstetrics \& Gynaecol. 2006;16(3):147-53.

7. Sobande AA, Eskander M, Archibong EI, Damole IO. Elective hysterectomy: A clinicopathogical review from Abha catchment area of Saudi Arabia. West African J Medic. 2005;24(1):31-5.

8. Kovac SR. Clinical opinion: guidelines for hysterectomy. American journal of obstetrics and Gynecol. 2004;191(2):635-40.

9. Fatehpuriya DS, Verma L, Sharma S. Clinicopathological study of hysterectomy in benign lesions: a study of 379 hysterectomies. International Journal of Reproduction, Contraceptive, Obstetrics and Gynecol. 2017;6:934-8.

10. Perveen S, Tayyab S. A clinicopathological review of elective abdominal hysterectomy. Journal of Surgery Pakistan (International). 2008;13(1):26-9.

11. Baral R, Sherpa P, Gautam D. Histopathological analysis of hysterectomy specimens: one year study. Journal of Pathology of Nepal. 2017;7(1):1084-6. 
12. Patel AS, Shah KJ. Histo pathological analysis of hysterectomy specimens in tertiary care center: two year study. Trop J Path Micro. 2018;4(1):34-9.

13. Suad MO. Zaid, Mazen ABT. Middle East Journal Of Internal Medic. 2017;10(1):17-24.

14. Patil T, Kulkarni MA, Anand AS, Punyashetty KB. Histomorphological study of lesions of corpus uteri in hysterectomy specimens: a tertiary care centre study. Trop J Path Micro. 2019;5(9):684-91.

15. Shaikh TA, Memon F, Memon Z. Hysterectomies; An Audit At A Tertiary Care Hospital. Professional Medical J. 2011;18(1).

16. Sachin AK, Mettler L, Jonat W. Operative spectrum of hysterectomy in a German university hospital. J Obstetrics And Gynecology India. 2006;56(1):59-63.

17. Subrata P, Srabani C, Anuradha S, Prakash PJ, Kingshuk B, Mrinal S. A retrospective clinico- pathological study of hysterectomy cases in a tertiary care hospital in India-a review of 950 cases. Bangladesh Journal of Medical Science. 2018;17(1):88-92.

18. Al-Kadri HM, Al-Turki AH, Mo AM. Short and long term complications of abdominal and vaginal hysterectomy for. Saudi Med J. 2002;23(7):806-10.

19. Sreedhar VV, Jyothi C, Sailaja V, Paul MC, Sireesha O, Vani T, Kumar KM. Histopathological Spectrum of Lesions of Hysterectomy Specimens-A Study of 200 Cases. Saudi J Pathol \& Microbiol. 2016;1(2):54-9.

Cite this article as: Meena M, Urvashi, Kachawaha CP, Fathepuriya DS. A clinical study of elective hysterectomies for benign lesions. Int J Reprod Contracept Obstet Gynecol 2021;10:2414-9. 